\title{
POTENTIAL FOR CLIMATE CHANGE MITIGATION THROUGH LOW-CARBON RAIL TRANSPORT IN INDIA
}

\author{
Priyanka Pali
}

The University of Manchester, United Kingdom

\begin{abstract}
Climate change is possibly one of the most urgent and complex issue being faced by nations worldwide. Rising levels of greenhouse gas emissions is considered by scientists and academics to be the primary cause for increasing temperatures, which is known to result in global warming and cause climatic changes. Therefore, adopting measures and strategies to mitigate the adverse impacts being caused due to rising emissions is high on the agenda for policy makers and governments across the globe. Many sectors are responsible for feeding this rise in GHG emissions, including transport. In India, transport is the second largest greenhouse gas emitter from the energy sector. Despite the fact that a majority of GHG emissions in the Indian transport sector is from roadways, and rail transport is only responsible for 5\% of the total transport emissions, the exponential increase in rail emissions over the past few years makes it imperative to focus on strategies and technologies to reduce the same. While current research is being undertaken to increase the share of railways due to their carbon friendly nature in comparison to road transport, it is submitted that a deeper engagement with developing and using actual low-carbon alternatives is required, which can in-reality help in achieving reduced emissions, and consequently bring down the GHG emissions from rail transport in India. Low-carbon alternatives, such as use of clean fuels and electrification of the rail network, are now being developed with the aim to move from using carbon intensive sources of energy to environment friendly ones. This paper discusses these GHG emissions reduction strategies being implemented by the Indian government within the rail network to determine whether these are in-reality assisting or have the potential to assist in bringing down the GHG emissions from railways in India. This will also determine the scope of climate change mitigation from these low-carbon alternatives being adopted by the government in the Indian rail transport sector.
\end{abstract}

Keywords: climate change mitigation, low-carbon transport, Indian railways, carbon emissions

\section{Introduction}

Growing awareness among policy makers, academics, scientists and beyond regarding the problems and challenges posed by climate change to our society, is leading to an increase in finding ways and means to reduce and stabilize the increasing levels of greenhouse gas (GHG) emissions into the atmosphere. This is critical within transport as it is one of the sectors worldwide where $\mathrm{CO} 2 \mathrm{Eq}$ emissions are on the rise.

In India, the four main modes of transport, i.e. road, rail, navigation and airways, combined together are responsible for being the second largest source of GHG emissions within the energy sector, with a total of 142.04 million tons of CO2 Eq emissions released in 2007 (Chakrabarty and Chakraborty, 2017). Amongst these four modes of transport, though the contribution of railways is only 6.84 million tons of CO2 Eq which is $5 \%$ of the total emissions and is noticeably lower than road emissions which is responsible for $87 \%$ of total emissions from transport at 123.55 million tons of $\mathrm{CO} 2 \mathrm{Eq}$, it is crucial to also focus on controlling the 
release of $\mathrm{CO} 2 \mathrm{Eq}$ emissions from railways as rail emissions have seen a massive growth from 3.4 million tons of direct CO2 emissions in 2003-04 to 6.84 million tons of $\mathrm{CO} 2$ emissions in 2007 (Ministry of Environment and Forests, 2010).

One of the many ways to respond to this rise in $\mathrm{CO} 2 \mathrm{Eq}$ emissions from rail transport sector is through development of low-carbon means of rail transport across cities and countries. There are many direct and indirect potential benefits which can be realized from well-designed low-carbon alternatives, such as reduction in air pollution, enhanced mobility options and ease in traffic and congestion. These can be achieved by incorporating a low-carbon trajectory within rail transport, which can consequently provide a strong incentive for an aggressive, sustained and efficient move to a low-carbon economy.

Although environmental advantages of using low-carbon alternatives within the rail transport network are many, the key objective of this paper is to ascertain if there are any low-carbon alternatives being adopted by the Indian government to assist in reducing release of $\mathrm{CO} 2 \mathrm{Eq}$ emissions from railways, and whether these low-carbon alternatives in fact have the potential to positively impact the reduction of GHG emissions from the Indian rail network and support the Indian government's climate change mitigation targets. To respond to this, the paper will first start with a brief discussion on the current understanding on climate change mitigation, which will then be followed by elaborating on what India brings to the global platform to support climate change mitigation. This paper then proceeds on to discuss the ongoing low-carbon / green initiatives in railways being adopted by the Indian government, such as the use of renewable sources of energy and afforestation on railway land to increase carbon sinks, with an aim to determine whether these measures/initiatives in fact have the potential to enable or assist in controlling/reducing the increasing emissions from railways in India.

\section{Current understanding of climate change mitigation}

Climate change is possibly the most complex and urgent issue being addressed by countries worldwide. Though a global issue, the impacts of climate change are mostly felt at the local level. Most of the countries have collectively agreed to limit the global average temperature rise well below 2 degrees Celsius above preindustrial levels by signing and ratifying numerous international and multilateral agreements. This is also reflected in the Pairs Agreement on Climate Change 2015 (hereinafter the Paris Agreement), which was entered into force on 4 November 2016, and is a key international document adopting reduction in global temperature rise as its overarching climate goal.

To elaborate a little further on the different ways to tackle climate change, any response to climate change must revolve around one of the two possible approaches - mitigation (i.e. actions/measures which address climate change by reducing/stabilizing the rising levels of GHGs in the atmosphere) and adaptation (i.e. actions/measures which revolve around adapting to the already present effects and impacts of climate change).

This paper revolves around studying climate change mitigation, and a detailed study of academic literature and various environmental assessment reports indicate that any action to be categorized as climate change mitigation must fall into one of the following three categories -

- An action that reduces and curbs greenhouse gas (GHG) emissions;

- An action that increases sinks of GHGs; and

- An action that attends to the causes of climate change.

The main objective of this paper is to further the research in the area of climate change mitigation by gathering and studying the low-carbon actions and measures being undertaken by the Indian government at the domestic level to reduce the rising carbon emissions from rail transportation with an aim to determine if 
these measures are in-fact assisting the government in reducing $\mathrm{CO} 2 \mathrm{Eq}$ emissions from rail transport in India. To achieve this objective, the next section will briefly set the stage by elaborating on the efforts being undertaken by the Indian government to address climate change at the domestic level, which will be followed by a section on the specific actions being undertaken by the government to reduce $\mathrm{CO} 2 \mathrm{Eq}$ emissions from the Indian rail network.

\section{What does India bring to the global platform to support climate change mitigation?}

Countries have come together to set up intergovernmental organizations and signed treaties to address the problem of climate change. Some of the key ones adopted by them with an aim to stabilize the GHG concentration in the atmosphere and address climate change mitigation include the United National Framework Convention on Climate Change (UNFCCC), the Kyoto Protocol and the Paris Agreement. The Indian government has signed and ratified these three international documents, and consequently, has also pledged to undertake measures to reduce its GHG emissions intensity by setting up domestic emissions reduction targets.

In addition to signing and ratifying various international and multilateral agreements towards mitigating the harmful impacts of climate change ${ }^{1}$, it is important to undertake initiatives which can support the reduction in release of harmful GHGs at national, city and municipality levels. These initiatives are reflected in the Intended Nationally Determined Contributions (INDC), which are plans that clearly outline the national GHG emissions reduction targets and goals towards climate action, and were submitted by countries before the preparation and release of the Paris Agreement.

Despite the fact that because of being a non-Annex 1 country under the Kyoto Protocol India does not have legally binding emissions reduction targets (Thaker and Leiserowitz, 2014), it nevertheless plays an active role in achieving global climate goals by putting forward mitigation strategies and setting up domestic targets to achieve them. Aligning with global climate objectives set up under the Paris Agreement, the INDC released by the Indian government in 2015 in response to their commitment under the Paris Agreement clearly points out India's attempts and commitments to work towards a carbon friendly path. To this effect, the INDC includes climate measures such as voluntary goal of reduction of GDP's emissions intensity by 33-35\% below 2005 levels by 2030, increasing the share of electricity being generated from non-fossil fuels to $40 \%$, enhancing energy generation from renewable sources of energy to $175 \mathrm{GW}$ by 2022 , and enhancing its forest cover with an aim to absorb 2.5-3 billion tons of CO2 by 2030 (UNFCCC, 2015). A detailed discussion on the current status of these measures is a subject matter of another research, but this paper will now focus on the measures being adopted by the Indian government to respond to control the rising GHG emissions from railways in India.

\section{Ongoing green initiatives in railways being adopted by the Indian government}

As India aims to transition to a low-carbon economy, there are a number of green initiatives being planned by the Indian government to assist in reducing emissions intensity from the rail transport sector. They are at various stages of execution and a majority of them have stemmed up in response to the emissions reduction target set up by the Indian railways, which is a 33\% reduction in GHG emissions intensity below 2005 levels by 2030 . These are also being supported by the carbon friendly objectives set up for the transport in the INDC which pledges to develop a safe, smart and sustainable transport network focusing on emissions reduction and mitigation strategies from all modes of transport including railways. For instance, the INDC presents strategies and actions to meet its emissions reduction targets and achieve lower emissions intensity which includes plans to enhance the share of railways in land based transport from $36 \%$ to $45 \%$ and increase their

\footnotetext{
${ }^{1}$ See for example the Paris Agreement on Climate Change 2015.
} 
focus on development of mass rapid transit system such as Metrorail across different cities in India. An elaborate study of these strategies is beyond the scope of this paper, but the section below will now elaborate on the various ongoing green initiatives being undertaken by the government to improve the carbon efficiency and green quotient of the rail network in India. Whether these are actually assisting the Indian railways in reducing their emissions intensity and supporting the move towards establishing a low-carbon rail network will be discussed in the subsequent section.

\section{Emissions intensity reduction target}

As a part of its low-carbon strategy, the Indian railways has envisaged a target of $33 \%$ reduction in its emissions intensity below 2005 levels by 2030. This is in response to the national GHG emissions intensity reduction targets put forth by the Indian government, i.e. 33-35\% by 2030 from levels in 2005 . Efforts are underway by the Indian railways to achieve this target by focusing on measures such as improvement in rail traction energy and increased use of clean fuel, which will be deliberated upon in the subsequent paragraphs.

\section{Energy efficiency and conservation}

The railways in India are known to be one of the highest consumers of electricity (Konda et al., 2017). To meet this growing demand for energy required by the rail sector, the government has identified and implemented several strategies which revolve around the use of carbon friendly sources of energy, some of which have been discussed in the present paper, with an aim to improve the energy efficiency of rail transport. This use has resulted in a decrease, though very negligible, in its energy consumption from 18.25 billion kwh in 2014-15 to 18.22 billion $\mathrm{kwh}$ in 2015-16. This is notwithstanding the various measures being undertaken to enable massive growth of the rail network in India, in addition to efforts being initiated to increase the share of railways in Indian freight traffic from 36\% in 2016-17 to 45\% by 2030 (Ministry of Railways, 2017).

Further, the Indian railways is also undertaking measures to cut down the use of energy by replacing the existing lights and fans in non-traction areas with energy efficient LED lights and ceiling fans. This is resulting in a decrease in 2-3\% of electricity consumption on yearly basis (Ministry of Railways, 2017). Another key technology being introduced in the Indian railways is the use of regenerative braking in rail systems, which is known to potentially reduce energy consumption (A. González-Gil et al., 2013), and in the present context it has the potential to reduce up to 500 tons of $\mathrm{CO} 2$ on an annual basis (Ministry of Railways, 2016).

\section{Use of alternative fuel}

Use of alternative fuel such as biodiesel, bioethanol, liquefied natural gas (LNG) and compressed natural gas (CNG) play a crucial role in reducing the harmful environmental impacts being caused due to the growing use of fossil fuels as they have a lower carbon footprint compared to traditional fossil fuels which are being used for traction purposes (M.A. Hazrat et al, 2015). In response to the targets released by the Ministry of Railways towards the use of 5\% biodiesel as a fuel for locomotives in India in its 2016-17 railway budget, which also supports the government's intentions presented in the INDC to promote biofuels (UNFCCC, 2015), the Indian railways has already introduced measures aiming at 5\% of biodiesel blending with highspeed diesel across various parts of the country (Ministry of Railways, 2018). There is also a plan in the pipeline by the Indian railways to develop LNG locomotives by 2020 which will result in a substitution of $80 \%$ high speed diesel with LNG being used for locomotives in India. The use of CNG in locomotives as a dual fuel with diesel is also being promoted within the Indian rail network and the government has already started its use by converting the existing locomotives into dual fuel mode to run passenger trains across the country. 


\section{Renewable sources of energy}

The Indian railways have released a target of meeting $10 \%$ of its energy requirement from renewable sources of energy by 2020 (Ministry of Railways, 2009). Consequently, the government through relevant authorities, are setting up solar rooftop panels on railway buildings and constructing solar power plants which will provide up to $1000 \mathrm{MW}$ of energy which will be used for both traction and non-traction purposes (Ministry of Railways, 2018). Further, the 2015-16 Annual Report released by the Indian Railways lists installation of rooftop solar panels in 200 railways stations as a key target to be achieved by the government within the rail transport sector. In addition to solar power, the Indian railways is also planning to utilize wind energy by setting up windmill power plants which will provide up to $200 \mathrm{MW}$ of energy to meet the growing energy needs of the Indian railways (Ministry of Railways, 2018).

\section{Setting up of the Environment Management Directorate}

In a bid to protect the environment and keep a tab on the energy consumption by railways in India, the Ministry of Railways set up an exclusive Directorate for Environment Management in January 2015 which became operational in April 2015. This is a first of its kind effort being initiated at the ministerial level in India. The directorate is responsible for monitoring and ensuring effective consumption and conservation of water and energy resources, along with monitoring pollution control and use of alternative sources of energy within the Indian railways. It is also working on finding ways and means to reduce the use of diesel and other carbon intensive sources of energy, which is one of the primary causes of global warming and climate change. However, according to the information available from the Ministry of Railways, as of October 2017, the work being done by the directorate has mostly been in the field of cleanliness of stations and tree plantation, ${ }^{2}$ and concrete efforts towards pollution control and monitoring the use of carbon intensive sources of energy remains to be seen.

\section{Afforestation efforts to increase carbon sink}

Afforestation, which in the present context means increase in forest cover and planting of trees on vacant land owned by the Indian railways, is considered by academics and scientists as one of the significant ways to increase carbon sequestration and carbon storage (Whitehead, 2011). Presently, the Indian railways is undertaking initiatives to meet its intended target to plant 50 million saplings/trees by 2019-2020 through massive plantation drives on vacant railway land and alongside railway tracks (Ministry of Railways, 2018). These measures also support the Indian government's climate objectives under the INDC which aim at enhancing carbon sequestration by 100 million tons of CO2 Eq on an annual basis (UNFCCC, 2015).

\section{Other energy conservation initiatives}

Studies are being conducted worldwide to recognize the effect of electrification of railways on carbon emissions, which conclude that rail electrification has a positive impact on reducing direct GHG emissions from rail transportation (Jicheng He et al., 2011). In India, to reduce the dependence on high speed diesel which is being used to run rail locomotives, the government is incorporating strategies and undertaking numerous measures to electrify the Indian rail network by 2020, which will assist in reducing GHG emissions at the point of use. But there have also been studies which discuss the overall reduction of carbon emissions due to electrification and state that this electricity which is being used for traction purposes is typically being generated in coal based thermal power plants, which are highly carbon intensive (R. Ramanathan and J.K.

\footnotetext{
${ }^{2}$ Further details available online at http://www.indianrailways.gov.in/railwayboard/view section.jsp?lang=0\&id=0,1,304,366,1539. Date of access: $25 / 2 / 2018$
} 
Parikh, 1999). In the Indian context, more than two-thirds of the electricity being used for electric traction is being generated using coal (R. Ramanathan and J.K. Parikh, 1999), which will be discussed further in the section below. This will also throw light on whether or not the measures which have been discussed in this section are in-fact assisting the government in reducing harmful $\mathrm{CO} 2 \mathrm{Eq}$ emissions from rail transport in India.

\section{Are low-carbon alternatives in-fact reducing GHG emissions from rail transport in India?}

There are several green initiatives discussed above which are being undertaken by the Indian government to assist the railways in smoothly moving towards a low-carbon path. But their implementation and monitoring can become a challenge given the magnitude and volume of operations of the Indian railways. To answer the question put forward in this paper, i.e. whether the low-carbon alternatives and initiatives being adopted by the Indian railways are indeed helping the rail transport sector in reducing GHG emissions and thereby assisting in achieving the objectives set up towards mitigating climate change, it is submitted that a study of the current literature revealed a number of issues and barriers which arise and adversely affect rail sector's potential to assist the Indian government in achieving their climate change mitigation objectives. Based on the various available reports and academic articles (for example Rai et al., 2013), these issues are highlighted below:

\section{No law surrounding the use of renewable sources of energy in Indian railways}

Though the Indian government has set targets towards the use of renewable sources of energy, absence of laws regulating their consumption and other related aspects is a huge barrier which dampens the effective and efficient utilization of these carbon friendly sources of energy. Having a structured legal setup to stimulate and motivate their usage is much needed, which can also assist the government in achieving their climate change mitigation targets from the Indian rail network.

\section{Track electrification through electricity sourced from carbon intensive sources}

To reduce its carbon intensity, the Indian railways is gradually electrifying its rail route network, which is being attributed by the government as an environment friendly initiative resulting in reduced visible pollution levels (Konda et al., 2016). But a majority of electrification of the Indian rail network is being done using electricity from coal based thermal power plants which are highly carbon intensive due to the high ash content in coal (Rai et al., 2013). Therefore, it is important to understand the sources of procuring electricity for electrification of rail network in India, and it is submitted that there needs to be much more rigorous mechanisms and policies to ensure that the electricity for electric traction is being sourced from carbon friendly sources.

\section{Lack of standards for emission control for diesel locomotives}

Absence of emission standards for rail locomotives, whose primary fuel is diesel, which is high in emissions and low on energy efficiency (Ramachandra and Shwetmala, 2009), escalates the problem of rising carbon emissions from rail transport in India. In its Vision and Roadmap 2012, the Indian Railways Organisation for Alternate Fuels, which is a part of the Ministry of Railways, has clearly confirmed the lack of emission standards from diesel locomotives, which requires immediate attention to set-up and implement mechanisms to regulate and monitor them.

\section{Conclusion}

India's rail transport sector is a growing contributor to the country's carbon emissions. Realizing emissions reduction from this sector must therefore be a part of the response from Indian government to reduce harmful $\mathrm{CO} 2 \mathrm{Eq}$ emissions. Setting up and implementation of green initiatives, such as the use of renewables to meet 
up to $10 \%$ of rail energy and use of clean and alternative sources of energy to meet energy demands for traction and non-traction activities, are a central part of India's response to climate change mitigation from rail transport. However, as mentioned in the preceding section, this paper submits that these measures are in fact not really supplementing the government's efforts to reduce GHG emissions from railways in India. This clearly exhibits an urgent need to intensify focus of relevant governmental authorities towards implementing prominent and substantial measures to control/reduce the release of harmful carbon emissions from rail transport in India, which presently has very limited attention of policy makers mainly due to the constant focus on regulating emissions from motorized means of road travel in India. The lack of focus on rail transport is validated by absence of GHG emissions standards from locomotives and dearth of stringent laws regulating the release of GHG emissions from rail infrastructure, which is accompanied by lack of awareness amongst policymakers to reduce GHG emissions and implement carbon reduction measures across rail network in India. These also suppress the potential for climate change mitigation from the Indian rail transport sector. But undertaking certain actions can address this problem, and some of these which are relevant to present paper are:

- Setting up fixed-step timely targets towards the use of energy from renewable sources in Indian railways.

- Drafting an act/statute which can direct the use of alternative fuels in the Indian rail transport sector.

- Aggressively restraining the use of coal for power generation, which is currently being used to fuel electrification of railways in India.

- Setting-up standards for emission control for diesel locomotives which are at present being used in large numbers to run the Indian rail network.

Implementing these measures is not easy and will not come cheap. They will also require regular and efficient monitoring, along with levy of penalties/sanctions for any act of non-compliance by the relevant authority/party. But the benefits associated with them are many, which can assist in lowering down the costs currently being incurred by the government to source fossil fuels for running the Indian rail network, along with reducing the levels of air pollution and improving the livability for future generations.

\section{References}

Chakrabarty, R. and Chakraborty, S. (2017) 'COP21 and India' Intended Nationally Determined Contribution Mitigation Strategy' in Hossain, M., Hales, R. and Sarker, T. (eds.) Pathways to a Sustainable Economy: Bridging the Gap between Paris Climate Change Commitments and Net Zero Emissions. Springer, pp. 149-166.

González-Gil, A., Palacin, R., and Batty, P. (2013) 'Sustainable urban rail systems: Strategies and technologies for optimal management of regenerative braking energy', Energy Conservation and Management, 75, pp. 374388.

Hazrat, M.A., Rasul, M.G., and Khan, M.M.K. (2015) 'Biofuel: An Australian perspective in abating the fossil fuel vulnerability’, Procedia Engineering, 105, pp. 628-637.

He, J. and Xu, Y. (2011) 'Energy Saving and Emission Reduction Estimations of Electrified Railways in China', Advances in Climate Change Research, 2(4), pp. 211-217.

India's Intended Nationally Determined Contribution. Available from: http://www4.unfccc.int/ndcregistry/PublishedDocuments/India\%20First/INDIA\%20INDC\%20TO\%20UNFCC C.pdf [Accessed 7th March 2018].

India, Ministry of Environment and Forests (2010) India: Greenhouse Gas Emissions 2007.

India, Ministry of Railways (2012) Vision and Roadmap 2012.

India, Ministry of Railways (2017) Environmental Sustainability-Role of Indian Railways: Annual Report 201516. 
India, Ministry of Railways (2018) Towards a low carbon mass transportation system, Environmental Sustainability: Annual Report 2016-17.

Konda, C., Trivedi, S., and Shrimali, G. (March 2017) 'Decarbonization of Indian Railways', The New Climate Economy Working Paper.

Rai, V.K., Raman, N.S. and Choudhary, S.K. (2013) 'Thermal power plants: Policy framework for CO2 emissions reduction', International Journal of Engineering Research and Science \& Technology, 2(2), pp. 8288.

Ramachandra, T.V. and Shwetmala (2009) 'Emissions from India's transport sector: Statewise synthesis', Atmospheric Environment, 43(34), pp. 5510-5517.

Ramanathan, R. and J.K. Parikh (1999) 'Transport sector in India: an analysis in the context of sustainable development', Transport Policy, 6(1), pp. 35-45.

Thaker, J. and Leiserowitz, A. (2014) 'Shifting discourses of climate change in India', Climate Change, 123 (2), pp. 107-119.

Whitehead, D. (2011) 'Forests as carbon sinks - benefits and consequences', Tree Physiology, 31(9), pp. 893902. 